\title{
Comparison of two practical methods for seakeeping assessment of damaged ships
}

\author{
J. Parunov, M. Ćorak \& I. Gledić \\ Faculty of Mechanical Engineering and Naval Architecture, University of Zagreb, Zagreb, Croatia
}

\begin{abstract}
The purpose of the paper is to compare two simplified methods that may be used for modeling wave-induced motion and resulting structural loads of ship damaged in collision or grounding accident. The first method is the added mass method, in which it is assumed that the mass of the flooded seawater becomes integral part of the ship mass and moves with the ship. The second approach is the lost buoyancy method, where structure of damaged tanks and all of its contents are removed from the vessel. The former method is applicable for small damages while the latter is more suited for large damage extents. Response amplitude operators of vertical motions and hull girder vertical wave bending moments at amidships are calculated by the state-of-the-art linear 3D panel hydrodynamic code and compared to those for intact ship as the effect of damage is often neglected in computation of motions and wave loads of damaged vessel. An attempt of verification of procedures is done by comparison with seakeeping experiments on damaged warship, described in available literature.
\end{abstract}

\section{INTRODUCTION}

Rational structural design of ships should consider strength of the vessel both in intact and damage condition. Damage of merchant ship may occur due to collision with another ship, grounding or some other type of human mistake. In case of such an accident, the ship strength could be significantly reduced while still water loads may increase and could become considerable cause of the structural overloading (Luis et al. 2009, Khan and Das, 2008).

Not much research has been spent on wave loads of damaged ships. The main reason is that design requirements for global wave loads on damaged ship are much lower compared to the intact condition (Hirdaris et al. 2014). Thus, the IACS Harmonized Common Structural Rules (CSR-H) (IACS, 2012), are aimed at checking the hull girder ultimate bending capacity in the damaged state using partial safety factor for wave loads of 0.67 , while in the intact condition this factor reads 1.1. The reason for reduced partial safety factor in damaged condition is reduced exposure time and milder environmental conditions to be taken into account. While for intact ships the North Atlantic wave environment is usually adopted, local scatter diagrams are proposed, as applicable, for the reliability assessment of damaged ships as suggested by Luis et al. (2009). Reduced exposure time to environmental conditions after damage should also be considered before salvage to a safe location. For example, Teixeira and Guedes Soares (2010) proposed a time period of one week as the voyage duration of a damaged ship to dry-dock. They concluded that the mean extreme Vertical Wave Bending Moment (VWBM) of a Suezmax tanker is about $15 \%$ lower when the exposure time is reduced from one year in the North Atlantic to one week in European coastal areas. Although research on loads on damaged ships in waves is rare, motions of damaged ships are widely covered in the literature (e.g. Korkut et al. 2004).

Application of risk-based design methods that includes structural reliability of damaged ship requires rational evaluation of all pertinent random variables, including wave loads of damaged ship (Prestileo et al. 2013) that was the motivation for some of recent studies on that subject. Thus, Folsø et al. (2008) have performed seakeeping computations on a damaged ship by the 3D linear hydrodynamic method. The damage scenarios corresponded to water ingress into the forepeak and/ or the double hull ballast tanks of the ship sailing in full load. For the case of the flooded ballast tank in the midship area, they obtained Response Amplitude Operators (RAOs) of the VWBM larger than those evaluated for the intact condition. Interesting conclusion from the paper is that keeping a bow quartering encounter angle, with the higher freeboard on the weather side, minimizes VWBM.

Lee et al. (2012) applied a computational tool based on a two dimensional linear method to predict the hydrodynamic loads of damaged warship. 
They obtained larger VWBM for damaged, compared to the intact ship. The global dynamic wave induced loads calculated using 2D linear method were also compared to measurements. In head and stern quartering waves, differences between computations and measurements of global dynamic wave induced load response amplitudes were reasonable. In general, however, linear strip theory overestimated measurements for both intact and damaged ship.

The analysis of wave loads on damaged ship is performed also by Downes et al. (2007) where it has be shown that the RAO peak value of VWBM increases, with increasing damage size and heel angle. It can also be seen however, that there is no significant difference between the RAOs due to the effects of damage. That study indicated that the change in global hull loading may be much smaller for tankers than for Ro-Ro ferries and cruise ships. Two practical methods for modeling wave-induced motion and resulting structural loads of damaged ship are proposed in that paper. The first method is the added mass method, in which it is assumed that the mass of the flooded seawater becomes integral part of the ship mass and moves with the ship. The second approach is the lost buoyancy method, where structure of damaged tanks and all of its contents are removed from the vessel. The former method is applicable for small damages while the latter is more suited for large damage extents. The hydrodynamic interaction between the waves and the structure of the opening remains after removing the tank from the ship hull, which needs to be modeled in the lost buoyancy method.

In past studies, reviewed in preceding paragraphs, only the added mass method was employed for hydrodynamic analysis of damaged ship. Results of damaged ship seakeeping assessment using the lost buoyancy method are not available from the literature. That was the motivation for the present study, aiming to investigate what could be difference if the lost buoyancy method is used instead of the added mass method. The calculations are performed on the example of the Aframax oil tanker using Hydrostar 3D panel seakeeping software (Bureau Veritas, 2012). Damage cases are generated according to the MEPC recommendations (IMO, 2003). Two mentioned methods for seakeeping assessment of damaged ship are compared and comparison is also performed with respect to the intact ship.

As there is a need for validation of methods, comparison with published and well documented experiment on damaged warship is also performed (Lee et al. 2012).

It should be clarified that employed methods do not consider the possibility of motion of the floodwater inside damaged tanks and coupling with the ship motion. Such analysis, which is presented e.g. by Santos and Guedes Soares (2008a, 2008b), Jia and Moan (2012) and Rodrigues and Guedes Soares (2014), is outside the scope of the present paper.

\section{DESCRIPTION OF SHIP AND DAMAGE CASES}

The studied ship is Aframax oil tanker with main particulars presented in Table 1. Cargo hold area is divided into 6 pairs of Cargo Tanks (CT) and 6 corresponding pairs of Water Ballast Tanks (WBT) in double bottom and side. WBTs are divided into portside and starboard tanks by center line girder in double bottom. The general arrangement of the ship is shown in Figure 1, while the hydrodynamic panel model of the intact ship is presented in Figure 2. Wetted hull surface of the intact tanker is modelled with 4160 panels.

Table 1. Main particulars of the Aframax oil tanker.

\begin{tabular}{ll}
\hline Dimension & $\begin{array}{l}\text { Unit } \\
(\mathrm{m}, \mathrm{dwt})\end{array}$ \\
\hline Length between perp., LPP & 234 \\
Breadth, $B$ & 40 \\
Depth, $D$ & 20 \\
Draught, $T$ & 15 \\
Deadweight, DWT & 105000 \\
\hline
\end{tabular}

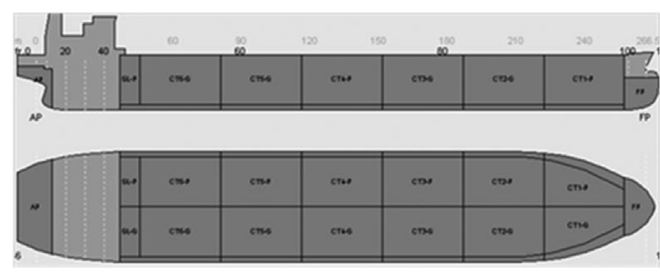

Figure 1. General arrangement of the Aframax tanker.

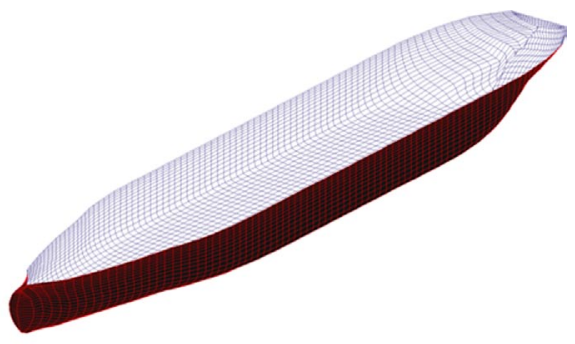

Figure 2. Hydrodynamic panel model of the intact tanker. 
As ship damage may occur in a number of ways, damage parameters are in general random quantities that may be described by probability distributions. Such probability distributions of damage size and location, for cases of the collision and grounding damages are proposed by International Maritime Organization (IMO, 2003).

In order to define credible damage scenarios, Monte Carlo (MC) simulation according to IMO probabilistic models is performed. 1000 random numbers are drawn according to IMO models and events resulting in damage of certain number of compartments are counted and presented in Figure $3 \mathrm{a}$ and $3 \mathrm{~b}$ for collision and grounding respectively. Figure 3 shows probabilities of damage in the longitudinal sense only, i.e. it is assumed that only WBTs are damaged, while damage does not penetrate through the inner bottom or inner hull. Fore peak tank and engine room are also considered as separate tanks in the present damage analysis.

Single tank damage in Figure 3 represents case when outcome of MC simulation results in the

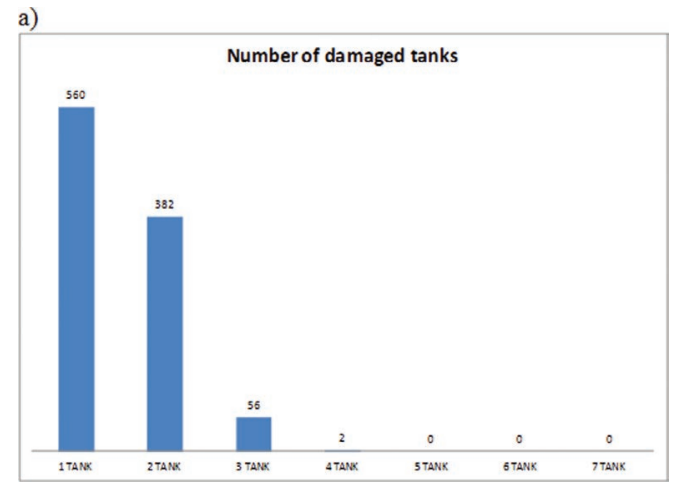

b)

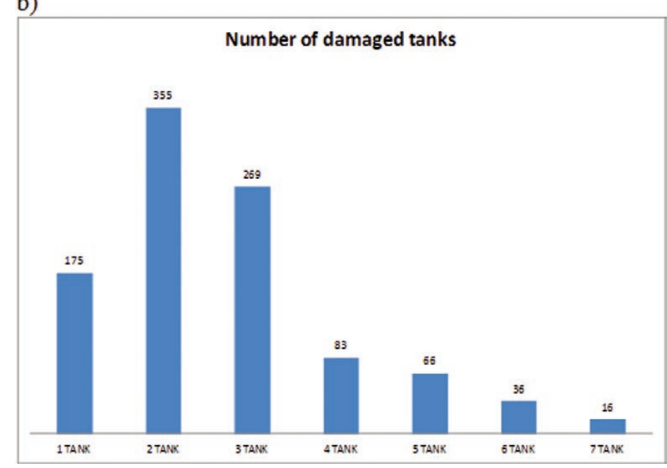

Figure 3. Probabilities of number of damaged tanks in the longitudinal direction a) collision; b) grounding. Values represent number of outcomes in 1000 simulations. damage of only one of WBTs or FP tank or engine room. Two tanks damage case means that $\mathrm{MC}$ simulation results in the damage of FP tank and WBT no.1, any combination of two consecutive WBTs or WBT no. 6 and the engine room. For damage of more tanks applies analogous reasoning.

Furthermore, it is to be noted that the collision always results in the asymmetrical damage, i.e. only starboard or portside tanks are damaged. For grounding, however, damage may be symmetrical, i.e. pairs of WBTs may be damaged together. Such conservative assumption is adopted in the present study, i.e. grounding damage is considered always as symmetrical damage.

It is interesting to notice from Figure 3 that damage of single compartment has the highest probability for collision, while damage of two pairs of compartments is the most probable scenario for grounding. There is a general trend obvious from Figure 3 that grounding damage is more extensive, i.e. there is a higher probability of damage of several compartments compared to collision.

For that reason, i.e. to cover the most severe cases, grounding damages are used in the comparative seakeeping assessment of damaged tanker in the present study. Two damage cases are used in the analysis: first one is the "small damage case" where grounding is assumed to damage only one pair of WBTs at amidships. The second case is the "large damage case" assuming that 3 pairs of WBTs at amidships are damaged. According to MC simulation, the small and large damage cases correspond to probability of occurrence of about $2 \%$ and $5 \%$ respectively. It is interesting to notice that the large damage case has higher probability of occurrence. That is visible also in Figure $3 b$ where it may be seen that probability that 3 consecutive tanks along ship will be damaged is larger than that only one single tank will be damaged.

Hydrostatic particulars for two damage cases are presented in Table 2. 3D panel hydrodynamic models for the lost buoyancy method and for two damage cases are shown in Figure 4. For the added mass method, the intact model (Figure 2) is used with modified mass distribution and hydrostatic particulars. It should be clarified that hydrostatic particulars (draught and trim) are the same for both methods.

Table 2. Hydrostatic particulars of damaged ship.

\begin{tabular}{llll}
\hline $\begin{array}{l}\text { Damage } \\
\text { case }\end{array}$ & $\begin{array}{l}\text { Flooded } \\
\text { mass }(\mathrm{t})\end{array}$ & $\begin{array}{l}\text { Draught } \\
(\mathrm{m})\end{array}$ & $\begin{array}{l}\text { Trim } \\
\left(^{\circ}\right)\end{array}$ \\
\hline $\begin{array}{l}\text { Small } \\
\text { Large }\end{array}$ & $\begin{array}{r}5577 \\
16596\end{array}$ & $\begin{array}{l}16.21 \\
17.38\end{array}$ & $\begin{array}{l}0.0 \\
1.04\end{array}$ \\
\hline
\end{tabular}


a)

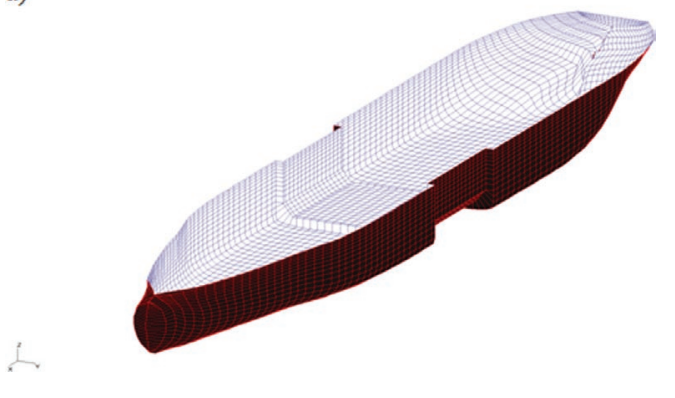

b)

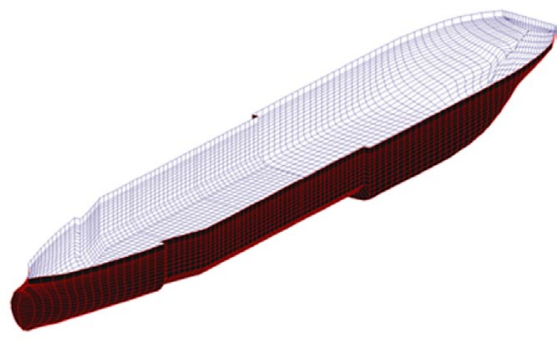

Figure 4. 3D panel hydrodynamic model for two damage cases for the lost buoyancy method a) small damage case; b) large damage case.

\section{RESULTS OF THE ANALYSIS}

\subsection{Comparison of ship motions}

For each of two damage cases as well as for intact ship, RAOs of heave and pitch motion are compared. RAOs of ship motion for damaged vessel are determined by the added mass method and the lost buoyancy method. In all cases, head seas are assumed and constant ship speed of 5 knots. Results of the comparative analysis are presented in Figure 5 and 6 for heave and pitch respectively.

It may be seen from Figures $5 \mathrm{a}$ and $6 \mathrm{a}$ that RAOs of ship motion for small damage case are almost identical for both methods of damaged ship analysis as well as for the intact vessel. The largest differences among methods may be noticed for heave motion and large damage case (Figure 5b). Differences appear mostly in the resonant region where the added mass method gives highest response, while the lost buoyancy method leads to the lowest RAO. Generally, it appears that discrepancies in pitch are lower compared to the heave motion.

\subsection{Comparison of VWBM at amidships}

For each damage case, RAOs of VWBM at amidships calculated for intact and for damaged ship are compared. RAOs of VWBM for damaged vessel are determined by the added mass method and a)

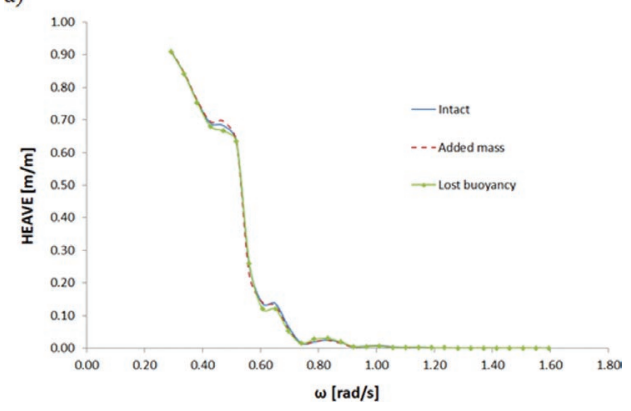

b)

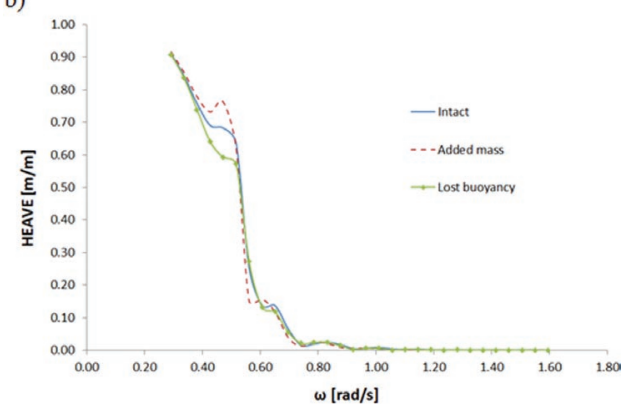

Figure 5. RAOs of heave motion for a) small damage case; b) large damage case.

a)

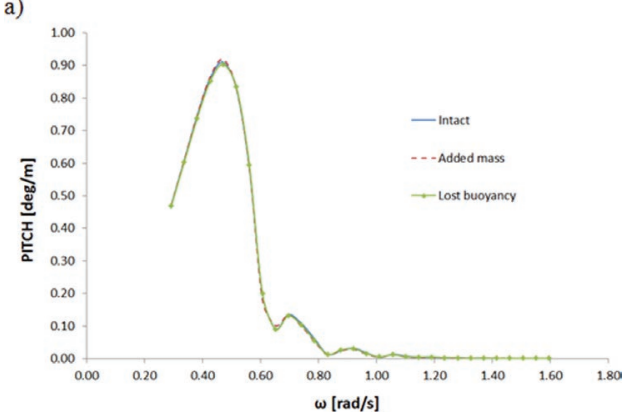

b)



Figure 6. RAOs of pitch motion for a) small damage case; b) large damage case. 
the lost buoyancy method. As for the ship motions, head seas are assumed and constant ship speed of 5 knots. Results of the analysis are presented in Figure 7.

It may be seen from Figure $7 \mathrm{a}$ that for small damage case RAOs of VWBM are very similar for intact ship and for both methods for assessment of damaged ship, while maximum values of RAOs are almost identical.

For large damage case, Figure $7 \mathrm{~b}$, there are some differences in RAOs of VWBM, while maximum value of RAO for damaged ship is larger compared to the intact vessel. Also, it may be seen that maximum RAO value for the added mass method is larger compared to the lost buoyancy method.

The general trend of presented results is very similar to Figure 2 of Downes et al. (2007), where the added mass method was used for modeling of flooding water.

\subsection{Influence of the heel angle on the response}

The effect of inclination of ship damaged by asymmetrical damage should also be mentioned. The effect of heel angle is not considered in the comparative analysis for two reasons. First is that heel angle is in first place consequence of the collision

a)

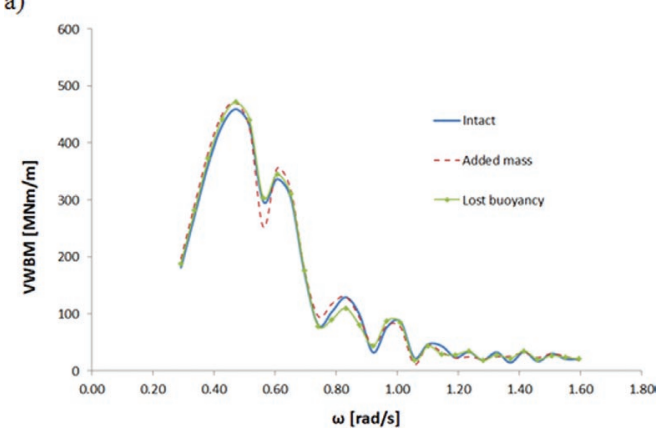

b)

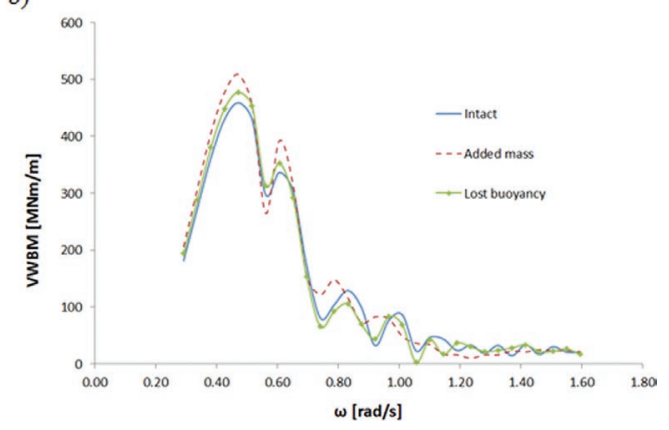

Figure 7. RAOs of VWBM for a) small damage case; b) large damage case. damage, while extents of collision damages are generally lower compared to the grounding damage. That may be clearly seen from Figure 3 . Secondly, while it is relatively simple to implement the added mass method for heeled ship, it is somewhat difficult to create and balance hydrodynamic model for the lost buoyancy method. That is the case especially for large heel angles.

In order to assess effect of the heel of damaged ship, RAOs of VWBM for asymmetrical collision damage of the oil tanker, are calculated using the added mass method and presented in Figure 8. RAOs are compared to the results for intact ship that are shown in the same figure. Two damage cases are presented, small collision damage with damaged WBT 4 (SB) and large collision damage with damaged WBT 3 and 4 (SB). Only head seas and small forward speed of 5 knots are considered. Hydrostatic particulars of damaged ship for two cases are presented in Table 3.

It may be seen in Figure 8 that differences in RAOs for intact and inclined damaged ship for head seas are almost negligible.

However, even in linear calculations of heeled ship, differences could be observed between VWBM calculated for heading angles symmetrical with respect to head or following seas. Extensive analysis of such differences is presented by Folsø et al. (2008). Noticeable differences of VWBMs between waves coming from portside and starboard are reported for heel angles larger than $10^{\circ}$. If waves are encountered on side with higher

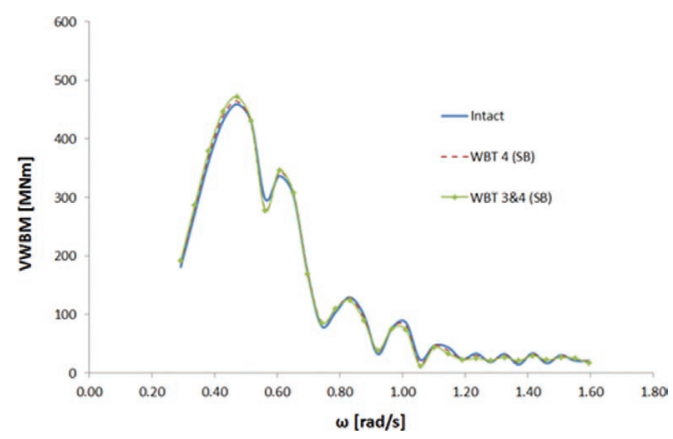

Figure 8. RAOs of VWBM for tanker damaged by collision damage.

Table 3. Hydrostatic particulars of ship damaged by collision.

\begin{tabular}{llll}
\hline $\begin{array}{l}\text { Damage } \\
\text { case }\end{array}$ & $\begin{array}{l}\text { Flooded } \\
\text { mass }(\mathrm{t})\end{array}$ & $\begin{array}{l}\text { Draught } \\
(\mathrm{m})\end{array}$ & $\begin{array}{l}\text { Heel } \\
\left({ }^{\circ}\right)\end{array}$ \\
\hline Small & 2788 & 15.9 & 3.2 \\
Large & 5577 & 16.21 & 6.4 \\
\hline
\end{tabular}


freeboard, VWBMs are much lower. Such analysis has not been performed within the present study.

\section{VALIDATION}

Validation of methods for prediction of wave loads on damaged ship is difficult because of the lack of experimental data. One of the rare well documented experiments including global wave loads on damaged ship is described by Lee et al. (2012). The towing tank experiments have been carried out using a model with a scale of $1 / 100$ of a Notional US Navy Destroyer Hull 5415. The tests measured 6 degree of freedom motion responses of the stationary model without forward speed, as well as global loads in intact and damaged conditions for different headings in regular waves. Several damage cases are used, as described in details by Lee et al. (2012). Only damage case 2, having biggest consequences on dynamic response on waves is considered herein. Also, in the present paper, only VWBM at amidships for head seas are compared.

3D panel hydrodynamic models of the intact and damaged ship are shown in Figure 9. Wetted hull surface of intact destroyer is modelled with 822 panels. As in the case of tanker analysis described in Section 3, damaged hydrodynamic model is used for the lost buoyancy method, while for the added mass method intact model is used with modified mass distribution and hydrostatic particulars.

RAOs of VWBM are presented in Figure 10a and $10 \mathrm{~b}$ for intact and damaged ship respectively.

a)

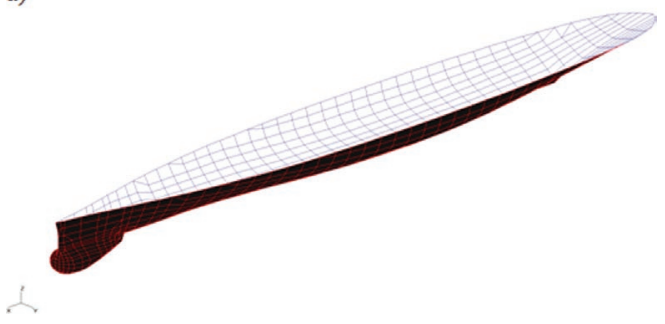

b)

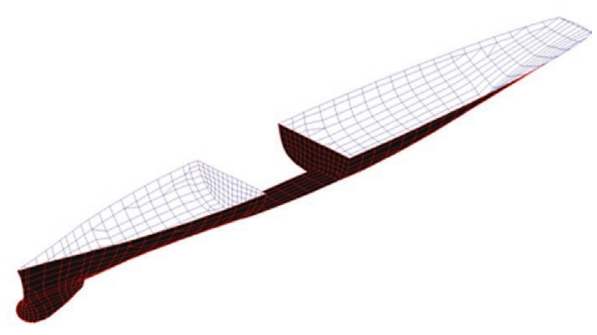

Figure 9. 3D panel hydrodynamic model of destroyer for a) intact ship; b) damaged ship.

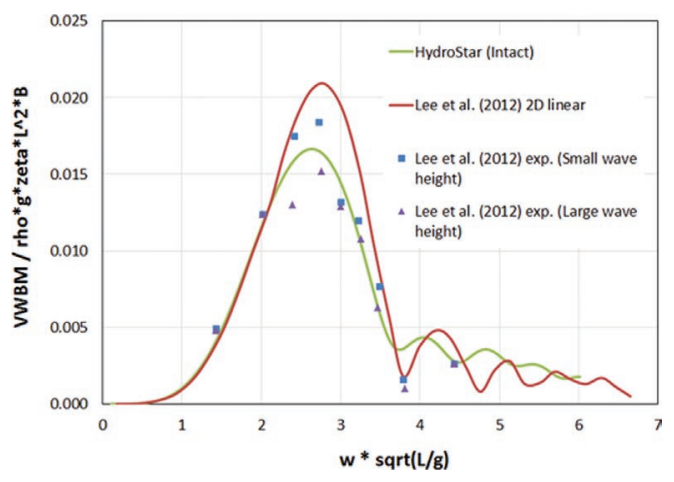

b)

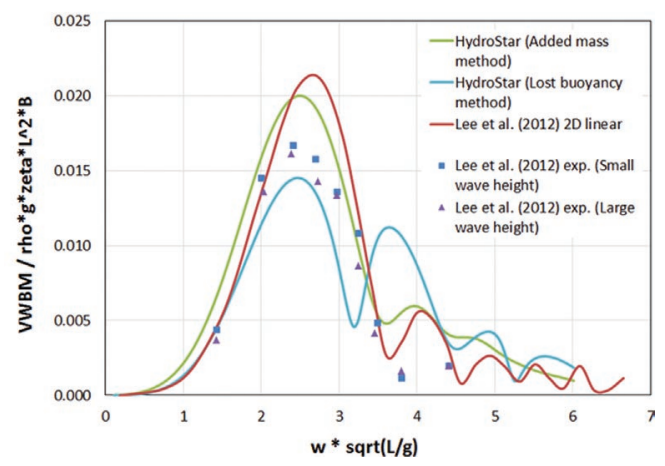

Figure 10. Transfer functions of VWBM for a) intact destroyer; b) damaged destroyer.

Figures include experimental results and also results obtained by 2D linear strip theory calculations performed by Lee et al. (2012).

It may be seen from Figure 10a that transfer functions of VWBM for intact ship obtained by linear 3D panel method agrees better to experimental results compared to $2 \mathrm{D}$ linear strip theory. While 2D method overestimates experimental results, 3D panel method provides RAOs that are placed between measurements for small and large wave heights. Such results are in line with previous findings reported in many references that linear strip theory overestimates experimental transfer functions (e.g. Parunov \& Senjanović, 2003).

In Figure 10b, there is again trend that $2 \mathrm{D}$ results overestimate measurements. $3 \mathrm{D}$ results for both methods for damage modeling are in somewhat better agreement to measurements compared to 2D calculations. For most of frequencies considered, the added mass method overestimates while the lost buoyancy method underestimate measured RAOs. It is also interesting to notice that differences between measured RAOs of VWBM for 
large and small wave heights are much smaller for damaged than for intact ship.

\section{DISCUSSION}

Some remarks should be put on the accuracy of the presented results. In first place it is to be noted that only linear results are considered. The main consequence of non-linearity is difference between sag and hog VWBM and these differences are more pronounced for ships with fine body lines and increase with increasing wave height. With that respect, it is interesting to notice that nonlinear effects are reduced for damaged warship (Figure 10b) compared to intact ship (Figure 10a). This is seen from smaller differences between measurements for large and small wave height for damaged than for intact ship. For tanker case, which is in the focus of the present paper, it is expected to have even smaller non-linear effects because of the large block coefficient.

The next aspect disserving attention is the influence of the sloshing of the liquid in damaged compartments. There is a lot of uncertainty and lack of research in this field. Jia and Moan (2012) concluded that the effect of sloshing on vertical bending moment is small except in beam seas, while the effect of sloshing on horizontal bending moment is large, especially in beam seas. The time domain theoretical approach to the coupled problems of ship and water inside compartment motions is described by Santos and Guedes Soares (2008a). They concluded that the dynamic roll moment is much larger than the static roll moment, for high wave frequencies.

Another aspect that should be mentioned and which is not included in the present analysis is the increased influence of horizontal components of global wave flexural loads. As pointed out by Folsø et al. (2008), this sums up with the presence of a horizontal component of static loads, due to the heel angle as well. Horizontal wave bending moment as well as torsional moments and other global wave load components of damaged vessel need further investigation.

Finally, the effect of structure of opening on hydrodynamic interaction with the waves is also neglected and deserves further research.

\section{CONCLUSIONS}

The aim of the paper is comparison of two simplified methods that may be used for modeling waveinduced motion and resulting structural loads of ship damaged in collision or grounding accident. While the added mass method is widely used and described in literature, experience in application of the lost buoyancy method almost does not exist.

For the case of Aframax tanker, it was shown that RAOs of VWBM at amidships increase with increase of damage size. The added mass method systematically provides larger maximum RAOs compared to the lost buoyancy method.

Validation of methods is performed by comparison with experiments on damaged warship, available from the published literature. Results of comparative analysis indicate that both methods result in RAOs of VWBM at amidships comparable to the measured values. However, the added mass method produce larger RAOs while the lost buoyancy method result in slightly lower values compared to the experimental RAOs of VWBM.

\section{ACKNOWLEDGEMENTS}

This work has been supported in part by Croatian Science Foundation under the project 8658.

\section{REFERENCES}

Bureau Veritas, 2006. HYDROSTAR User's manual, Paris.

Downes, J., Moore, C., Incecik, A., Stumpf, E., and McGregor J. 2007. A Method for the quantitative Assessment of Performance of Alternative Designs in the Accidental Condition, 10th International Symposium on Practical Design of Ships and Other Floating Structures, Houston, Texas.

Folsø, L., Rizzuto E., and Pino E. 2008. Wave Induced Global Loads for a Damaged Vessel, Ships and Offshore Structures, Volume 3, No.4, pages 269-287.

Hirdaris, S., Argiryiadis, K., Bai, W., Dessi, D., Ergin, A., Fonseca, N., Gu, X.,Hermundstad,O.A.,Huijsmans, R., Iijima, K., Nielsen, U.D., Papanikolau, A., Parunov, J., and Incecik, A. 2014. Loads for use in the design of ships and offshore structures, Ocean engineering, 78, pp. 131-174.

IACS, 2012. Harmonized Common Structural Rules, External release, 1st July 2012.

IMO Revised, 2003. Interim guidelines for the approval of alternative methods of design and construction of oil tankers under Regulation $13 \mathrm{~F}(5)$ of Annex 1 of MARPOL 73/78, Resolution MEPC 2003;110(49), Annex 16.

Jia, H., and Moan, T. 2012. The Effect of Sloshing in Tanks on the Hull Girder Bending Moments and Structural Reliability of Damaged Vessels. Journal of Ship Research, Vol. 56, No. 1, pp. 48-62.

Khan, I.A., and Das, P.K. 2008. Reliability analysis and damaged ships considering combined vertical and horizontal bending moments, Ships and Offshore Structures, Volume 3, No. 4 (2008), pp. 371-384.

Korkut, E., Atlar, M. \& Incecik, A. 2004. An experimental study of motion behaviour with an intact and damaged Ro-Ro ship model, Ocean Engineering, Vol. 31, pp. 483-512. 
Lee, Y., Chan, H.-S., Pu, Y., Incecik, A., and Dow, R. S., 2012. Global wave loads on a damaged ship, Ships and Offshore Structures, 7(3). pp. 237-268.

Luis, R.M., Teixeira, A.P., and Guedes Soares, C., 2009. Longitudinal strength reliability of a tanker hull accidentally grounded, Structural Safety, Volume 31, Issue 3, pp. 224-233.

Parunov, J., and Senjanović, I., 2003. Incorporating Model Uncertainty in Ship Reliability Analysis., SNAME Transactions. 111; pp. 377-408

Prestileo, A., Rizzuto, E., Teixeira, A.P., and Guedes Soares, C., 2013. Bottom damage scenarios or the hull girder structural assessment, Marine Structures; 33, pp. 33-55.

Rodrigues, J.M., and Guedes Soares, C., 2014. Exact Pressure Integrations on Submerged Bodies in Waves Using a Quadtree Adaptive Mesh Algorithm. International Journal for Numerical Methods in Fluids; 76: 632-652. Santos, T.A., and Guedes Soares, C., 2008a. Study of Damaged Ship Motions Taking Into Account Floodwater Dynamics. Journal of Marine Science and Technology; 13: 291-307.

Santos, T.A., and Guedes Soares, C., 2008b. Global Loads due to Progressive Flooding in Passenger Ro-Ro Ships and Tankers. Ships and Offshore Structures; 3(4): 289-302.

Teixeira, A.P., and Guedes Soares, C. 2010. Reliability assessment of intact and damaged ship structures. In: Guedes Soares, C., Parunov, J. (Eds.), Advanced Ship Design for Pollution Prevention. Taylor and Francis Group, London, ISBN:978-0-41558477-7. 